\title{
A two-year audit of non-vascularized iliac crest bone graft for mandibular reconstruction: technique, experience and challenges
}

\author{
Kelvin Omeje ${ }^{1}$, Akinwale Efunkoya, Ibiyinka Amole, Benjamin Akhiwu, Daniel Osunde ${ }^{2}$ \\ ${ }^{1}$ Department of Oral and Maxillofacial Surgery, Aminu Kano Teaching Hospital, Kano, \\ ${ }^{2}$ Department of Dental Surgery, University of Calabar Teaching Hospital, University of Calabar, Calabar, Nigeria
}

\begin{abstract}
J Korean Assoc Oral Maxillofac Surg 2014;40:272-277)
Objectives: Non-vascularized iliac crest bone graft (NVIBG) is a known treatment option in mandibular reconstruction following jaw resection, but no documented review of patients treated with NVIBG exists for northern Nigeria. The experience and technique from a Nigerian tertiary hospital may serve as baseline data for comparison and improvement of practice for other institutions.

Materials and Methods: A retrospective review of medical records and patient case files from January 2012 to December 2013 was undertaken. All case files and other medical records of patients who had reconstruction with NVIBG for benign or malignant lesions with immediate or delayed reconstruction were selected for review.

Results: Twenty patients had mandibular reconstruction with NVIBG during the study period. Two patients were excluded because of incomplete medical records. Eighteen patients' (male=14, female=4) records were reviewed. Their ages ranged from 13 to 62 years (mean $26.0 \pm 10.6$ years). Indications for NVIBG included jaw tumors $(\mathrm{n}=16 ; 88.3 \%)$, jaw cyst $(\mathrm{n}=1 ; 5.6 \%)$ and gunshot injury $(\mathrm{n}=1 ; 5.6 \%)$. Jaw tumors seen were ameloblastoma $(\mathrm{n}=15 ; 83.3 \%)$ and osteosarcoma $(\mathrm{n}=1 ; 5.6 \%)$. Treatments done were mandibular resection with condylar resection $(\mathrm{n}=7 ; 38.9 \%)$, mandibular segmental resection $(\mathrm{n}=10 ; 55.6 \%)$ and subtotal mandibulectomy $(\mathrm{n}=1 ; 5.6 \%)$. Patients' postoperative reviews and radiographs revealed good facial profile and continued bone stability up to 1 year following NVIBG.
\end{abstract}

Conclusion: NVIBGs provide an acceptable alternative to vascularized bone grafts, genetically engineered bone, and distraction osteogenesis for mandibular reconstruction in resource-limited centers.

Key words: Mandibular resection, Mandibular reconstruction, Non-vascularized iliac crest bone graft [paper submitted 2014. 7. 15 / revised 2014. 8. 16 / accepted 2014. 9. 7]

\section{Introduction}

Mandibular resection is a major treatment modality for many destructive mandibular lesions resulting from tumors, cysts, infections, irradiation and trauma ${ }^{1,2}$. The aesthetic and functional roles of the mandible make its reconstruction a significant component of treatment following resection. The literature documents various options for mandibular reconstruction $^{2-8}$. These include use of non-biologic materials (al-

\footnotetext{
Akinwale Efunkoya

Department of Oral and Maxillofacial Surgery, Aminu Kano Teaching Hospital, PMB 3452, No 2, Zaria Road, Kano 700001, Nigeria

TEL: +234-8065454401

E-mail:akinefunks@gmail.com
}

(a) This is an open-access article distributed under the terms of the Creative Commons Attribution Non-Commercial License (http://creativecommons.org/licenses/(by-nc/3.0/). which permits unrestricted non-commercial use, distribution, and reproduction in any medium, provided the original work is properly cited.

Copyright (C) 2014 The Korean Association of Oral and Maxillofacial Surgeons. All rights reserved. loplastic implants) and biologic materials that may be from other species (xenografts) or the same species (homografts) as the recipient. Grafts from the same individual (autografts) may be vascularized or non-vascularized, and are more popular than the other available options ${ }^{6}$. Additional options for mandibular reconstruction include tissue engineering ${ }^{5}$ and bone transport distraction osteogenesis ${ }^{3}$.

The use of genetically-engineered bone substitutes and distraction osteogenesis are not practical in most poorly resourced economies, mostly due to a lack of facilities and relevant skills ${ }^{5,7}$. Similarly, the use of vascularized bone grafts for mandibular reconstruction may not be feasible in developing countries because of the huge financial implication of very long theater sessions, and lack of necessary equipment, facilities and surgical expertise ${ }^{1,9}$.

The advantages of non-vascularized iliac crest bone graft (NVIBG) include an adequate bulk of tissue for mandibular reconstruction, ease of harvest, possibility of a two-team ap- 
proach and biomechanical similarity to the mandible. The iliac crest is thus a frequently favored site of bone harvest when compared with the rib, calvaria, scapula or fibula for mandibular reconstruction ${ }^{10}$. In spite of its popularity for mandibular reconstruction, as evidenced by several international reports ${ }^{6,7,10,11}$, the literature from Nigeria is sparse, and the few existing studies on this subject appear to have been carried out in southwestern Nigeria ${ }^{2,9,12}$.

NVIBGs are frequently used for mandibular defect reconstruction at Aminu Kano Teaching Hospital in Kano, Nigeria. A retrospective review of all cases seen in our center between January 2012 and December 2013 was undertaken to review our experience with this technique. The aim of this study is thus to report on the technique and describe our experience and challenges with NVIBG for mandibular reconstruction.

\section{Materials and Methods}

A retrospective review of medical records from January 2012 to December 2013 was undertaken. All case files and radiologic records of patients who had immediate or delayed reconstruction with NVIBG during this period were selected for review. Cases without complete medical records were excluded from the review. Patient demographic information, preoperative histological diagnosis and postoperative events, including infection and complications, also were collected from the case files. Reconstruction was grouped into immediate or delayed depending on whether it was carried out at the time of ablation or at a later date after the initial surgical excision.

Mandibular defects were categorized into three groups for the purpose of this review. This categorization was based on a classification by Boyd et al. ${ }^{13}$ involving three groupings, namely $\mathrm{H}, \mathrm{L}$ and $\mathrm{C}$ representing 'lateral defects of any length up to the midline that includes the condyle,' 'lateral defects that excludes the condyle', and 'defects that involve the central segment with four incisors and two canines,' respectively. Harvested iliac crest bone grafts were anchored to a 2.5-mm, non-locking reconstruction plate (Orthomax, Navadurga, Gujarat, India) for all cases. The study protocol was exempted from review by our institutional ethics and research committee. The data were analyzed using simple frequencies and percentages for categorical variables, and mean and standard deviation for continuous variables.

\section{Procedure/harvest of non-vascularized iliac crest bone graft}

All the surgeries were performed under general anesthesia following routine scrubbing and draping. One team performed the surgeries: The same maxillofacial surgery team that excised the tumors also harvested the graft. Tumor excision was done by a combined intraoral and extraoral approach. Intraoral incisions were sulcular relieving incisions, while extraoral incisions varied from a submandibular incision to a visor approach (bilateral continuous submandibular incision) depending on the extent of the lesion. The dimension of the mandibular defect was measured before resection for lesions that had not breached the lower border of the bone, or after resection with the jaws stabilized in occlusion for lesions that had distorted the normal mandibular symmetry. Half of this length was transferred to the iliac crest for harvest.

Only anterior iliac crest grafts were used for reconstruction in all cases. Patients were positioned supine with a sand bag underneath the gluteal region to highlight the iliac bone. After marking the area with a surgical pen, the operation site was infiltrated with $1: 200,000$ adrenaline in saline at the iliac crest region for hydro-dissection and vasoconstriction. The incision was made and carried down to the periosteum to expose the iliac bone (a gentle upward pull of the skin over the iliac crest before the incision was made hides the incision beneath the 'bikini-line'). Harvest of the grafts was done 1 $\mathrm{cm}$ posterior to the anterior superior iliac spine (ASIS). This shift away from the ASIS prevents inadvertent fracture of this portion of the spine. The tissues were retracted away from the deep surface of the iliac crest on the medial side to prevent damage to the abdominal viscera.

Bone harvest was achieved using two vertical stop cuts placed on either end of the required length, using an osteotome combined with a traversing horizontal cut.(Figs. 1, 2) Several gentle knocks were used to complete the cuts to prevent visceral injuries. Medullary chips were routinely harvested from the iliac crest to augment the butts at the graftgraft intersection. Following harvest of the graft, bone-wax was cemented over the bone cut surfaces and the incision was closed with sutures. An improvised drain (two-way urethral catheter anchored to a urine bag) was used at the donor site for all patients and was removed 2 to 4 days postoperatively depending on the activity of the drain. Long acting local anesthesia ( $0.5 \%$ plain Marcaine) was routinely administered at the harvest site to reduce postoperative pain. 


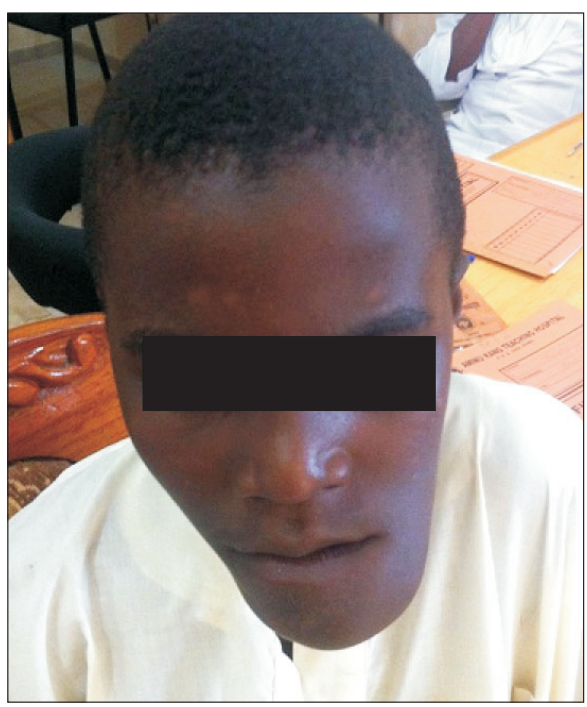

Fig. 1. Preoperative photograph of a 17-year-old boy with mandibular ameloblastoma.

Kelvin Omeje et al: A two-year audit of non-vascularized iliac crest bone graft for mandibular reconstruction: technique, experience and challenges. J Korean Assoc Oral Maxillofac Surg 2014

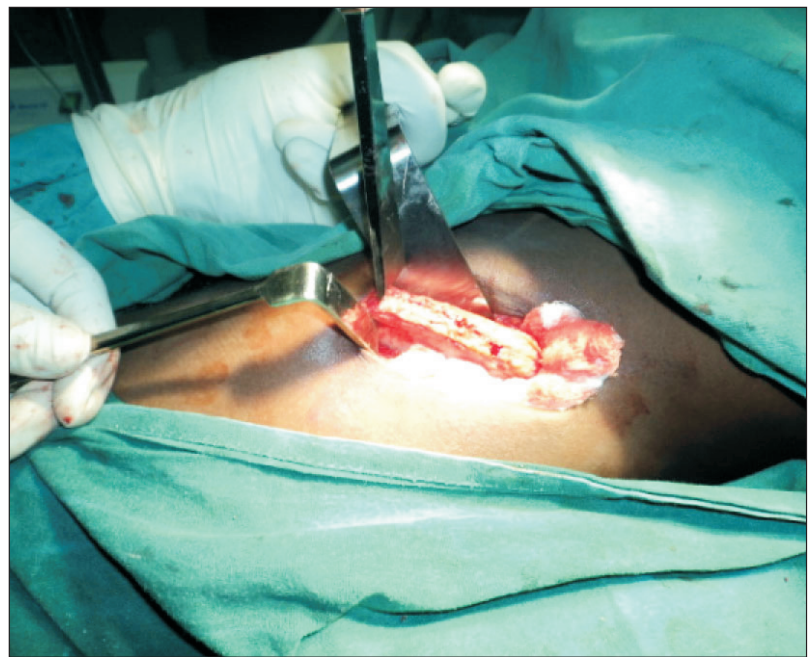

Fig. 2. The iliac crest exposed and vertical stops placed bilaterally at the required length.

Kelvin Omeje et al: A two-year audit of non-vascularized iliac crest bone graft for mandibular reconstruction: technique, experience and challenges. J Korean Assoc Oral Maxillofac Surg 2014

A bi-cortical wedge of iliac crest bone with intervening medullary component was harvested and split longitudinally into two monocortical-medullary halves to complete the required length for the defect. The cortical component of each half was secured successively facing the buccal surface and anchored to $2.5-\mathrm{mm}$, non-locking stainless steel reconstruction plates.(Fig. 3) Various suturing techniques were utilized for closure of intraoral and extraoral incisions, ranging from

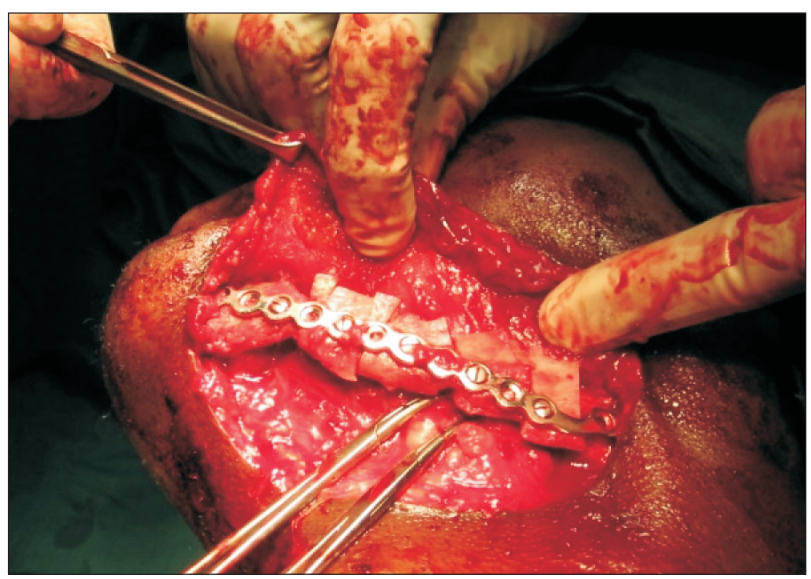

Fig. 3. Harvested bone transposed to recipient bed, secured and the cortical surface oriented buccally in a similar patient.

Kelvin Omeje et al: A two-year audit of non-vascularized iliac crest bone graft for mandibular reconstruction: technique, experience and challenges. J Korean Assoc Oral Maxillofac Surg 2014

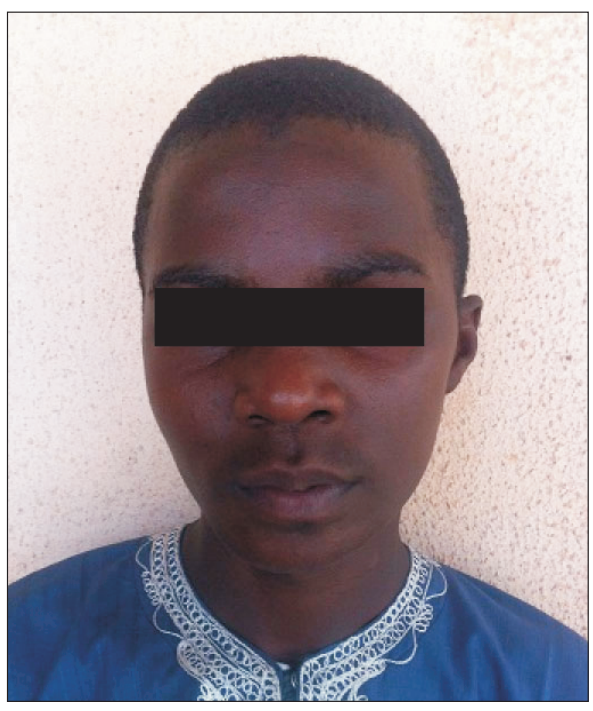

Fig. 4. Postoperative photograph of same patient in Fig. 1 following mandibular resection and reconstruction with non-vascularized iliac crest bone graft.

Kelvin Omeje et al: A two-year audit of non-vascularized iliac crest bone graft for mandibular reconstruction: technique, experience and challenges. J Korean Assoc Oral Maxillofac Surg 2014

simple interrupted, continuous locking, and continuous nonlocking to horizontal mattress stitches.(Figs. 4, 5)

All the patients had maxillomandibular fixation wires on the contralateral side and were left for a minimum of 1 month postoperatively. Intraoperative antibiotics ( $2 \mathrm{~g}$ Rocephine) were given in all cases as prophylaxis and continued postoperatively as $1 \mathrm{~g}$ twice daily for 7 days. Patients were reviewed following mandibular reconstruction with NVIBGs after discharge at intervals of 2 weeks, 1 month, 3 months, 6 
Table 1. Patient demographics, date of surgery, site and size of lesion, duration of admission and follow-up

\begin{tabular}{|c|c|c|c|c|c|c|c|}
\hline $\mathrm{S} / \mathrm{N}$ & Pathologic entity & $\begin{array}{l}\text { Sex/age } \\
(y r)\end{array}$ & $\begin{array}{c}\text { Date of surgery } \\
\text { (day/mo/yr) }\end{array}$ & Site & $\begin{array}{l}\text { Size of defect } \\
(\mathrm{cm})\end{array}$ & $\begin{array}{c}\text { Duration of } \\
\text { admission (day) }\end{array}$ & $\begin{array}{l}\text { Follow-up } \\
\text { (mo) }\end{array}$ \\
\hline 1 & Ameloblastoma & $\mathrm{M} / 20$ & $11 / 01 / 12$ & $\mathrm{~L}$ & 4 & 7 & 12 \\
\hline 2 & Ameloblastoma & $F / 25$ & $21 / 02 / 12$ & $\mathrm{~L}$ & 5 & 8 & 14 \\
\hline 3 & Ameloblastoma & $\mathrm{M} / 19$ & $20 / 03 / 12$ & $\mathrm{~L}$ & 5 & 10 & 12 \\
\hline 4 & Ameloblastoma & $\mathrm{F} / 30$ & 04/04/12 & $\mathrm{L}$ & 6 & 12 & 12 \\
\hline 5 & Ameloblastoma & $\mathrm{M} / 21$ & $02 / 05 / 12$ & $\mathrm{~L}$ & 6 & 11 & 12 \\
\hline 6 & Gunshot & $\mathrm{M} / 13$ & $19 / 06 / 12$ & $\mathrm{~L}$ & 5 & 10 & 12 \\
\hline 7 & Ameloblastoma & $\mathrm{M} / 30$ & $17 / 07 / 12$ & $\mathrm{~L}$ & 5 & 9 & 16 \\
\hline 8 & Ameloblastoma & $\mathrm{M} / 32$ & $15 / 08 / 12$ & $\mathrm{~L}$ & 5 & 7 & 12 \\
\hline 9 & Ameloblastoma & $\mathrm{F} / 21$ & $25 / 09 / 12$ & $\mathrm{~L}$ & 8 & 8 & 13 \\
\hline 10 & Ameloblastoma & $\mathrm{M} / 33$ & $26 / 09 / 12$ & $\mathrm{~L}$ & 5 & 8 & 12 \\
\hline 11 & Ameloblastoma & $\mathrm{M} / 17$ & $16 / 10 / 12$ & $\mathrm{C}, \mathrm{H}$ & 12 & 14 & 12 \\
\hline 12 & Ameloblastoma & $\mathrm{M} / 20$ & $21 / 11 / 12$ & $\mathrm{H}$ & 10 & 10 & 13 \\
\hline 13 & Dentigerous cyst & $F / 23$ & $05 / 12 / 12$ & $\mathrm{H}$ & 9 & 10 & 14 \\
\hline 14 & Ameloblastoma & $\mathrm{M} / 25$ & $29 / 01 / 13$ & $\mathrm{H}$ & 10 & 14 & 12 \\
\hline 15 & Ameloblastoma & $\mathrm{M} / 29$ & $20 / 02 / 13$ & $\mathrm{H}$ & 10 & 10 & 12 \\
\hline 16 & Ameloblastoma & $\mathrm{M} / 24$ & $19 / 03 / 13$ & $\mathrm{H}$ & 10 & 11 & 12 \\
\hline 17 & Osteosarcoma & $\mathrm{M} / 27$ & $03 / 04 / 13$ & $\mathrm{H}$ & 8 & 8 & 12 \\
\hline 18 & Ameloblastoma & $\mathrm{M} / 62$ & $24 / 04 / 13$ & $\mathrm{H}$ & 8 & 8 & 12 \\
\hline
\end{tabular}

(M: male, F: female, L: lateral defects without condyle, C: central defects including canines, H: lateral defects including condyle)

Kelvin Omeje et al: A two-year audit of non-vascularized iliac crest bone graft for mandibular reconstruction: technique, experience and challenges. J Korean Assoc Oral Maxillofac Surg 2014
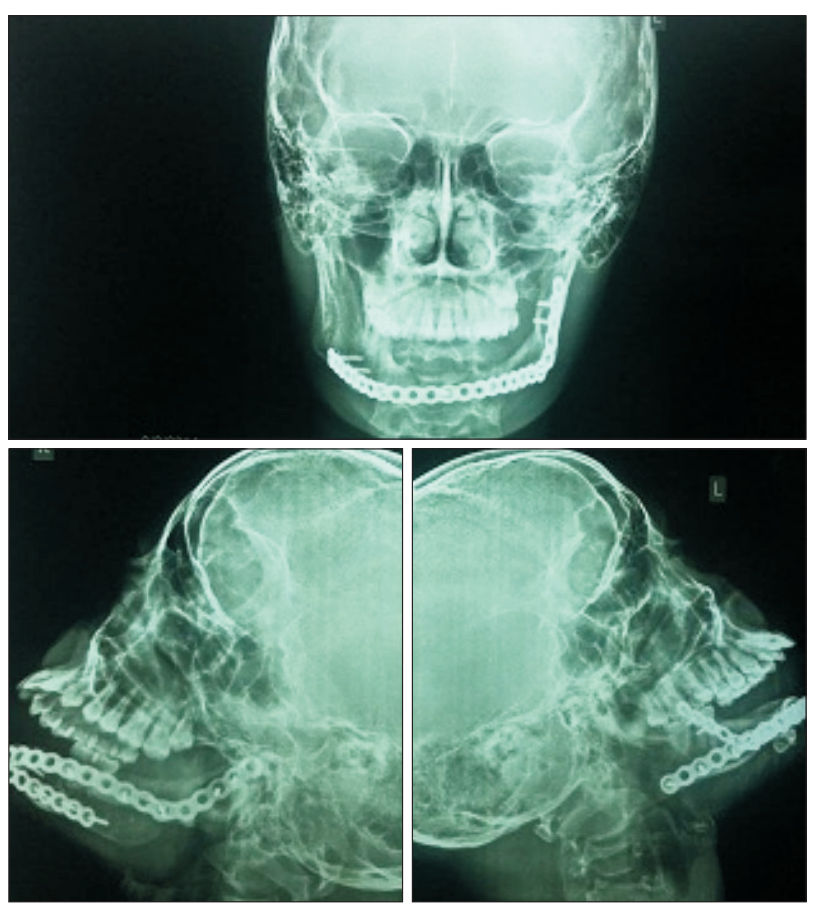

Fig. 5. Postoperative radiograph of same patient in Fig. 1 one year after reconstruction with nonvascularized iliac crest bone graft. Kelvin Omeje et al: A two-year audit of non-vascularized iliac crest bone graft for mandibular reconstruction: technique, experience and challenges. J Korean Assoc Oral Maxillofac Surg 2014

months, and 1 year. Radiographs were used to evaluate patient progress at the 2-week, 6-month and 1-year postoperative reviews.

\section{Results}

A total of 20 patients had mandibular reconstruction with NVIBG during the study period. Complete records relating to two cases could not be retrieved, and thus these cases were excluded from this audit. Eighteen patient records were reviewed (male : female=14:4). The ages of patients studied ranged from 13 to 62 years with a mean of $26.0 \pm 10.6$ years. (Table 1)

Indications for NVIBG in these 18 patients included jaw tumors $(n=16 ; 88.3 \%)$, jaw cyst $(n=1 ; 5.6 \%)$ and gunshot injury $(n=1 ; 5.6 \%)$. There was concordance between all preoperative and postoperative histopathology reports. Jaw tumors seen were primarily ameloblastomas $(n=15 ; 83.3 \%)$ and osteosarcomas $(n=1 ; 5.6 \%)$. A dentigerous cyst required jaw resection (due to the extensive bone destruction of the mandible), and an NVIBG was used to reconstruct the defect. One patient sustained a gunshot injury requiring removal of nonvital bone segments and replacement with a NVIBG. Seventeen patients had immediate reconstruction with NVIBG, while one patient had delayed reconstruction. This patient was referred from another facility after mandibular resection for reconstruction at our center. Seven patients (38.9\%) had mandibular resection with condylar head disarticulation, and 10 patients $(55.56 \%)$ had segmental resection, while only one patient $(5.6 \%)$ had subtotal mandibulectomy.

The minimum and maximum duration of hospital stay were 7 days and 14 days, respectively, with an average stay of 10 
days.(Table 1) Complications included wound dehiscence $(n=2 ; 11.1 \%)$, paresthesia of the thigh $(n=10 ; 55.6 \%)$, gait disturbance $(n=7 ; 38.9 \%)$ and fistula/sinus formation $(n=2$; $11.1 \%$ ). Intraoral wound dehiscence was seen in two patients, while one patient had wound dehiscence at the iliac crest region. Wound infection was observed to add an average of 4 days to the average hospital stay. This was observed in the two patients with fistula/sinus formation.

All patients with gait disturbance and paresthesia had complete resolution of these problems at their 1-month postoperative review. All patients were reviewed for a minimum of 12 months.(Table 1) Radiographic review of all the patients at 12 months showed that only one patient $(5.6 \%)$ had significant bone resorption necessitating re-treatment.

\section{Discussion}

Limited experience with distraction osteogenesis, the absence of materials and technical know-how for geneticallyengineered bone substitutes and micro-vascular composite flaps make NVIBGs a viable treatment option for mandibular reconstruction in resource-limited regions of the world. Tumor resection necessitating reconstruction is fairly common in resource-poor economies. The use of NVIBGs for the reconstruction of these defects is a skill that can be mastered. The high male prevalence in mandibular ablation and iliac crest reconstruction in our study is typical for such centers ${ }^{14-16}$ and is similar to the findings of Okoje et al. ${ }^{12}$ and Ogunlade et al. $^{9}$.

The indication for mandibular resection in our study was mostly ameloblastoma (83.3\%). This is slightly different from but comparable to the finding of Ogunlade et al. ${ }^{9}$ from southwestern Nigeria, where ameloblastoma accounted for $73 \%$ of their cases. This is likely due to the high prevalence rate of ameloblastoma in these regions and its significant facial disfigurement necessitating resection.

Most of our patients had immediate reconstruction. This was likely because aesthetics was a strong indication for surgery. Our technique involves the harvest of bicortical blocks of bone from the iliac crest that is later split longitudinally. The rationale behind splitting the bone graft is to increase the amount of bone available for reconstruction, yet reduce the amount of bone harvested from the iliac crest. This ultimately reduces donor site morbidity. A 'split iliac crest bone graft' has been described by Lee et al. ${ }^{17}$ for mandibular reconstruction. The length of the defect created following ablation in our study ranged from 4 to $12 \mathrm{~cm}$. Pogrel et al. ${ }^{6}$ in their study observed a $75 \%$ failure rate for long-span defects measuring more than $12 \mathrm{~cm}$ and advised vascularized grafts for such reconstruction. The low rate of bone resorption seen in our study was comparable to that documented by Ogunlade et al. ${ }^{9}$. This may be related to the young age of the patients and the relatively short span of their defects. Other factors may include 'rigid' immobilization of the graft on a reconstruction plate, prophylactic antibiotic administration, extended postoperative antibiotic use and probably the benign nature of the lesions in most of our subjects. Lee et al. ${ }^{17}$ corroborated our findings in their retrospective review of donor-site morbidity of anterior iliac crest for reconstruction of the jaw, and concluded that split-thickness bone harvest from the inner table of the anterior iliac crest is a well-accepted procedure with relatively low morbidity. Lee et al. ${ }^{17}$, however, retained the outer split portion of the iliac crest in situ (only using the inner half for mandibular reconstruction), while both inner and outer halves were utilized in our study.

The postoperative hospital stay following iliac crest bone graft is often part of our routine monitoring of a patient after general anesthesia in order to monitor postoperative pain, to observe gut function after abdominal surgery and to monitor general recovery of patients. Extension to this period, which resulted from postoperative infection in our study, should be guarded against, especially in regions with poor economic resources where increased hospital stay adds to patients' bills. Factors that may predispose to postoperative infection include poor aseptic technique, poor oral mucosal seal with salivary contamination of grafts, mobility of grafts, and absence of prophylactic antibiotics.

Harvest of iliac crest bone has been known to be associated with complications, such as nerve injuries, fracture of the ilium, penetrating abdominal injuries and hematoma at the donor site ${ }^{7,9}$. Several precautions can be employed in the harvest of iliac crest bone grafts to minimize these complications. These precautions include using gentle knocks; placing stop cuts when harvesting bone; presence of an effective drain system, preferably an active drain system; and careful retraction and protection of abdominal viscera. Complications following NVIBG as seen in our study were similar to reports from other parts of Nigeria ${ }^{9,12}$. In the present study, wound dehiscence (from an intraoral wound or at the iliac crest) was minimal and responded well to both local debridement and antibiotics. Absence of paresthesia and gait disturbance at 1-month post-surgery review showed that gait disturbance and paresthesia that were observed were likely from early postoperative pain and inflammation rather than neurovascu- 
lar transection.

Reconstruction of the mandible after resection with condylar disarticulation without joint replacement has constituted a major challenge in our reconstructive repertoire. Placement of a reconstruction plate with condylar prosthesis into a shallow glenoid fossa may lead to displacement and deviation during function. Postoperative facial symmetry is a possible challenge of NVIBG anchored on a reconstruction plate, especially those traversing the mental region. Absence of stereolithographic studies to produce computer-aided contouring and adaptation of reconstruction plates often produces imperfections in symmetry following reconstruction. We practice freehand contouring of reconstruction plates, which can be both tedious and subject to imperfections.

The relative ease of a two-team approach for tumor ablation, harvesting and reconstruction with NVIBG may make this technique preferable to scapular free flap to some surgeons, though the scapular free flap has excellent cutaneous three-dimensional versatility and tissue match ${ }^{18}$. The singleteam approach employed in our study was because of the relative paucity of maxillofacial surgeons in our region. This single-team approach may easily lead to fatigue because of the long duration of such surgeries.

\section{Conclusion}

Mandibular tumors necessitating ablative surgeries are common in our environment. A simple methodical approach for harvesting iliac bone can consistently provide an affordable alternative to mandibular reconstruction in the absence of microvascular tissue replacement and genetically-engineered bone substitutes. Challenges with the use of NVIBGs for mandibular reconstruction include gait problems, infection and possible facial asymmetry.

\section{Conflict of Interest}

No potential conflict of interest relevant to this article was reported.

\section{References}

1. Head C, Alam D, Sercarz JA, Lee JT, Rawnsley JD, Berke GS, et al. Microvascular flap reconstruction of the mandible: a comparison of bone grafts and bridging plates for restoration of mandibular continuity. Otolaryngol Head Neck Surg 2003;129:48-54.

2. Obiechina AE, Ogunlade SO, Fasola AO, Arotiba JT. Mandibular segmental reconstruction with iliac crest. West Afr J Med 2003;22:46-9.

3. Takahashi T, Fukuda M, Aiba T, Funaki K, Ohnuki T, Kondoh T. Distraction osteogenesis for reconstruction after mandibular segmental resection. Oral Surg Oral Med Oral Pathol Oral Radiol Endod 2002;93:21-6.

4. McCarthy JG, Schreiber J, Karp N, Thorne CH, Grayson BH. Lengthening the human mandible by gradual distraction. Plast Reconstr Surg 1992;89:1-8; discussion 9-10.

5. Abukawa H, Shin M, Williams WB, Vacanti JP, Kaban LB, Troulis MJ. Reconstruction of mandibular defects with autologous tissueengineered bone. J Oral Maxillofac Surg 2004;62:601-6.

6. Pogrel MA, Podlesh S, Anthony JP, Alexander J. A comparison of vascularized and nonvascularized bone grafts for reconstruction of mandibular continuity defects. J Oral Maxillofac Surg 1997;55:1200-6.

7. Tidstrom KD, Keller EE. Reconstruction of mandibular discontinuity with autogenous iliac bone graft: report of 34 consecutive patients. J Oral Maxillofac Surg 1990;48:336-46.

8. Burkey BB, Coleman JR Jr. Current concepts in oromandibular reconstruction. Otolaryngol Clin North Am 1997;30:607-30.

9. Ogunlade SO, Arotiba JT, Fasola AO. Autogenouscortico-cancellous iliac bone graft in reconstruction of mandibular bone defects: point of technique. Afr J Biomed Res 2010;13:157-60.

10. O'Brien CJ, Archer DJ, Breach NM, Shaw HJ. Reconstruction of the mandible with autogenous bone following treatment for squamous carcinoma. Aust N Z J Surg 1986;56:707-15.

11. Kurz LT, Garfin SR, Booth RE Jr. Harvesting autogenous iliac bone grafts. A review of complications and techniques. Spine (Phila Pa 1976) 1989;14:1324-31.

12. Okoje VN, Obimakinde OS, Arotiba JT, Fasola AO, Ogunlade SO, Obiechina AE. Mandibular defect reconstruction with nonvascularized iliac crest bone graft. Niger J Clin Pract 2012;15:224-7.

13. Boyd JB, Gullane PJ, Rotstein LE, Brown DH, Irish JC. Classification of mandibular defects. Plast Reconstr Surg 1993;92:1266-75.

14. Mehta RP, Deschler DG. Mandibular reconstruction in 2004: an analysis of different techniques. Curr Opin Otolaryngol Head Neck Surg 2004;12:288-93.

15. Egyedi P. Wound infection after mandibular reconstruction with autogenous graft. Ann Acad Med Singapore 1986;15:340-5.

16. Kudo K, Shoji M, Yokota M, Fujioka Y. Evaluation of mandibular reconstruction techniques following resection of malignant tumors in the oral region. J Oral Maxillofac Surg 1992;50:14-21.

17. Lee SH, Choi SY, Kim HS, Kwon TG, Kim CS, Lee SH, et al. Donor site morbidity of anterior iliac crest for reconstruction of the jaw. J Korean Assoc Oral Maxillofac Surg 2010;36:380-4.

18. Coleman SC, Burkey BB, Day TA, Resser JR, Netterville JL, Dauer E, et al. Increasing use of the scapula osteocutaneous free flap. Laryngoscope 2000;110:1419-24. 